\title{
INVESTIGATIONS OF MENINGOCOCCAL INFECTION. I. BACTERIOLOGICAL ASPECTS ${ }^{1}$
}

\author{
By LEWIS THOMAS 2 AND JOHN H. DINGLE \\ (From the Thorndike Memorial Laboratory, Second and Fourth Medical Services (Harvard), \\ Boston City Hospital, and the Departments of Medicine and of Bacteriology and \\ Immunology, Harvard Medical School, Boston)
}

(Received for publication October 6, 1942)

Since the early part of this century, the literature dealing with the meningococcus and meningococcal infection has included intensive studies of the clinical, laboratory, and epidemiological aspects of the subject (1). Much of this early work was carried out during and after the last war, under the combined stimulus of wartime epidemics and the development of serum therapy. There followed a period of several years during which epidemics of meningococcal meningitis were uncommon, and investigations of the organism were limited to a comparatively few laboratories. In recent years, particularly since the advent of the present war, general interest in meningococcal infection has been reawakened and its potential importance among the infectious diseases has received new appreciation.

Despite extensive work with the meningococcus, many fundamental problems remain unsolved. Little is known, for example, regarding the nature of the factors which lead to the development of meningitis, to meningococcemia without meningitis, to the symptomless carrier state, and to no infection whatever. Much also remains to be learned regarding the specific biological characteristics which determine the pathogenicity of meningococci, the means by which the infected host is enabled to combat infection, the mechanism of natural immunity to the meningococcus, and the mechanism and durability of acquired immunity. The eventual solution of such problems will require a considerable amount of new data, which can only be obtained and correlated through clinical, bacteriological, immunological, and epidemiological methods of investigation.

In the hope of contributing further information in these directions, concurrent studies employing

\footnotetext{
1 This study was aided in part by a grant from the William W. Wellington Memorial Research Fund.

2 Fellow of the Frederick Tilney Memorial Fund.
}

these methods have been undertaken in a group of 42 cases of epidemic and endemic meningococcal infection. Both organisms and sera were available for study from most of these cases. Some were sporadic cases in the city of Boston, while others were seen during an epidemic of meningococcal meningitis in Halifax, Nova Scotia. Certain clinical and epidemiological aspects of the epidemic cases have already been reported $(2,3)$, and a more detailed study of the other cases will be the subject of a later report. All degrees of severity of illness were observed, ranging from mild, almost abortive infections, to the most fulminating type. In the majority of cases, the disease was moderately severe. All except 6 of the patients were adults. Two of the patients died; the rest recovered without any permanent sequelae. Most of the patients responded promptly to chemotherapy with either sulfadiazine or sulfapyridine. The temperature dropped during the first 2 or 3 days and symptomatic recovery occurred by the end of the first week. Only 3 of the patients were treated with therapeutic antiserum in addition to chemotherapy. In addition to these 42 cases, 15 carriers of meningococci and 60 normal contacts have also been studied.

The present report is concerned with the results of bacteriological investigation of this material; the immunological aspects have been considered separately $(4,5)$. The purposes of the bacteriological study have been (1) to examine certain general characteristics of all the strains of meningococci isolated, such as serological reactions, morphology, virulence for mice, and survival or growth in fresh normal serum, and (2) to compare, on the basis of these characteristics, the organisms isolated from the cerebrospinal fluid of cases and those from the nasopharynx of cases and carriers. 


\section{METHODS}

Thirty-nine strains of meningococci have been investigated, of which 25 were isolated during the Halifax epidemic and 14 were obtained in Boston; 20 of these 39 strains were from the cerebrospinal fluid of cases, 4 from the nasopharynx of cases, and 15 from the nasopharynx of contact carriers.

The meningococci from the cerebrospinal fluid and nasopharynx were isolated either on casein-hydrolysate-starch agar (6) or on blood agar, employing a candle jar. Blood cultures were made in beef-heart infusion broth. When cultures from the patients were made after chemotherapy had been instituted, para-aminobenzoic acid was added to the media $(7,8)$.

As soon as each organism had been identified and typed, a 6-hour growth was suspended in milk and stored in a number of sealed tubes in a carbon dioxide-ice chamber. No more than 4 subcultures of any strain were made between the time of isolation and final storage. For the subsequent bacteriological studies, these stored organisms were cultured directly on solid media, then transferred once or twice before use; in a few instances, virulence titrations were made with freshly isolated strains before storage. In all of the tests, cultures grown for no more than 6 hours were used.

The following procedures were employed:

1. The organisms were grouped by means of agglutination in standard grouping sera; readings were made after 2 hours at $37.5^{\circ} \mathrm{C}$. and 18 hours in the icebox. The meningococci have been designated as Group I (Types I and III of Gordon and Murray (9)) and Group II (Types II and IV). Also classed in Group II were a number of "atypical" carrier strains; these organisms fulfilled the cultural, morphological, and fermentative criteria for meningococci but typing by agglutination was inconclusive. Confirmation of the typing of the Groups I and II organisms was obtained through the kindness of Dr. Sara E. Branham, to whom samples of most of the strains were sent shortly after isolation.

2. Quellung (10) in specific antisera was used as an adjunct to grouping by agglutination.

3. Fermentation reactions were determined on agar media containing glucose, maltose, lactose, or sucrose. Solid media, containing phenol red as an indicator, were used.

4. Observations of the colonial and microscopic morphology of each strain were made and recorded.

5. The oxidase test (11) with para-aminophenylenediamine was performed with all strains.

6. The virulence of each strain for mice was determined by the use of mucin. A single lot of mucin, which had been found to be satisfactory in preliminary titrations, was used in testing all the strains. A 3 per cent suspension in distilled water was prepared by mixing in a Waring Blendor. This mixture was then autoclaved for 15 minutes at 15 pounds pressure, and the reaction adjusted to $\mathrm{pH}$ 7.4. Fresh suspensions of mucin were prepared every 2 or 3 days.
The organisms were grown for 6 hours on serumdextrose agar slants, then washed from the surface of the medium with beef-infusion broth and suspended in enough broth so that approximately $1,000,000,000$ organisms were contained in each milliliter of suspension. The turbidity of the final suspension was kept as nearly the same as possible for all of the organisms by the use of a photoelectric turbidometer. Serial dilutions from $10^{-1}$ to $10^{-6}$ were made in broth. Plate counts of the $10^{-6}$ to $10^{-8}$ dilutions were made in triplicate, by spreading $0.1 \mathrm{ml}$. of the broth uniformly over the surface of a blood-agar plate. Although the experimental error inherent in this method is granted, triplicate plate counts were found to check with fair consistency, averaging 100 colonies from $0.1 \mathrm{ml}$. of the $10^{-6}$ dilution. Although the assumption has been made for purposes of tabulation that each colony represents a single organism, it is realized that a colony may result from the growth of one or more organisms.

For the injection of mice, each broth dilution of $10^{-8}$ and beyond was diluted $1: 10$ in mucin, so that final dilutions of $10^{-4}$ to $10^{-6}$ were obtained. These 6 dilutions were injected intraperitoneally into mice, in $1 \mathrm{ml}$. amounts. Six mice were used for each dilution. White Swiss mice from a single breed, weighing between 14 and 16 grams, were used in all of the titrations.

Four strains of meningococci were tested each day; these included 3 strains of unknown virulence and 1 virulent strain which was selected as a standard control for all of the titrations. The mice were observed for 72 hours after injection, although in most instances the fatalities occurred within 36 hours. Cultures of the heart's blood were made from at least half of the mice dying in each titration and, with rare exceptions, these were always positive for the meningococcus. The 50 per cent endpoint for each titration was calculated by the method of Reed and Muench (12).

7. The ability to survive or to grow in fresh normal human serum was determined with 27 strains of meningococci from cases and carriers. These tests were made with the serum of a healthy adult male having a history of no previous meningococcal infection. Tenfold dilutions of young cultures of the organisms in broth were prepared, from $10^{-1}$ to $10^{-6}$, and $0.05 \mathrm{ml}$. of each dilution was added to $0.25 \mathrm{ml}$. of serum diluted $1: 2$, in small glass tubes. The tubes were then sealed and rotated in the incubator for $\mathbf{2 0}$ hours, after which they were opened and cultures from each tube were made on the surface of a blood-agar plate. The original dilutions of the organisms were prepared so that the $10^{-6}$ dilution contained approximately 50 organisms in $0.05 \mathrm{ml}$.

\section{RESULTS}

1. Grouping. The distribution of specific groups among the Boston and Halifax cases and carriers is shown in Table I. In the Halifax epidemic, all of the strains from cases were Group I, 3 carrier strains were Group I, and 10 carrier strains were Group II, or atypical men- 
TABLE I

Distribution of specific groups in Halifax (epidemic) and Boston (endemic) strains of meningococci

\begin{tabular}{l|c|c|c|c|c}
\hline \hline \multirow{2}{*}{ Source } & \multicolumn{2}{|c|}{ Halifax strains } & \multicolumn{2}{|c}{ Boston strains } \\
\cline { 2 - 5 } & I & II & I & II \\
\hline Cerebrospinal fluid of cases & 9 & 0 & 6 & 5 \\
Nasopharynx of cases & 3 & 0 & 1 & 0 \\
Nasopharynx of carriers & 3 & 10 & 2 & 0 \\
\hline
\end{tabular}

ingococci. In the Boston endemic cases, 7 strains were Group I and 5 were Group II. The 2 Boston carrier strains were Group I.

2. The quellung reaction was found to be of considerable value in the rapid grouping of fresh Group I meningococci. All of the strains which proved by agglutination to be Group I also exhibited capsular swelling in specific antisera when young cultures were used. It was found that this reaction could be enhanced to a notable degree if a small inoculum of organisms was allowed to grow for a few hours in heat-inactivated rabbit antiserum; by this method cultures grown for as long as 48 hours could be induced to show quellung after less than 4 hours' incubation in the antiserum. No quellung was observed with any of the Group II strains, although they were tested in several different lots of Group II antiserum.

3. Fermentation reactions. All of the strains produced fermentation of glucose and maltose, and failed to ferment sucrose or lactose.

4. Morphology. The colonial and microscopic morphology was similar in all of the Group I and Group II strains from cases, conforming to the classic descriptions of the meningococcus.

TABLE II

Mucin virulence of meningococci for mice

\begin{tabular}{|c|c|c|c|c|c|c|c|c|}
\hline \multirow{2}{*}{\multicolumn{2}{|c|}{ Source of strain }} & \multirow{2}{*}{ Group } & \multirow{2}{*}{$\begin{array}{c}\text { Num- } \\
\text { ber of } \\
\text { strains }\end{array}$} & \multicolumn{5}{|c|}{ Number of meningococci } \\
\hline & & & & 100 & ${ }_{500}^{101-}$ & $\begin{array}{l}501- \\
1000\end{array}$ & $\begin{array}{l}1001- \\
10,000\end{array}$ & $\begin{array}{l}\text { Over } \\
10,000\end{array}$ \\
\hline \multicolumn{2}{|c|}{$\begin{array}{l}\text { Cerebrospinal } \\
\text { - fluid }\end{array}$} & II & $\begin{array}{r}15 \\
5\end{array}$ & $\begin{array}{l}9^{*} \\
2\end{array}$ & $\begin{array}{l}2 \\
1\end{array}$ & 2 & $\begin{array}{l}1 \\
1\end{array}$ & $\begin{array}{l}1 \\
1\end{array}$ \\
\hline \multirow{2}{*}{$\begin{array}{c}\text { Naso- } \\
\text { pharynx }\end{array}$} & Cases & II & $\begin{array}{l}4 \\
0\end{array}$ & 1 & 2 & 1 & & \\
\hline & $\begin{array}{l}\text { Car- } \\
\text { riers }\end{array}$ & II & $\begin{array}{r}5 \\
10\end{array}$ & 4 & 1 & 1 & 3 & 6 \\
\hline
\end{tabular}

* The figures refer to the numbers of strains giving a 50 per cent end-point with the number of meningococci designated.
The colonies of 6 of the group II carrier strains from Halifax were smaller than usual on horse blood infusion-agar plates, and 2 of these had a faint yellowish pigmentation in older cultures.

5. Oxidase test. The colonies of all strains gave positive results with this test.

6. Virulence. The results of virulence titrations, expressed as the number of organisms constituting 50 per cent end-points, are shown in Table II. Strains with titers of 100 organisms or less are considered to be highly virulent. Endpoints of more than 1000 indicate moderate or questionable virulence, and those over 10,000 are assumed to be avirulent.

The Group I organisms, from both sporadic and epidemic cases, with 2 exceptions, were virulent. The exceptions were 2 strains of organisms of relatively low virulence from 2 sporadic cases in Boston. In such a small series of cases, this difference is of only speculative interest. The nasopharyngeal strains of Group I, whether derived from cases or carriers, were quite as virulent as the cerebrospinal fluid strains. Furthermore, in 3 cases from which both cerebrospinal fluid and nasopharyngeal organisms were isolated, no striking difference between the two strains was found. The titers of these strains are shown in Table III. Although in the case of J. C. there is ap-

TABLE III

\begin{tabular}{|c|c|c|}
\hline \multicolumn{3}{|c|}{$\begin{array}{l}\text { Comparison of mouse virulence of strains of Group I } \\
\text { meningococci from the cerebrospinal fluid and } \\
\text { nasopharynx of the same individuals }\end{array}$} \\
\hline & \multicolumn{2}{|c|}{$\begin{array}{l}\text { Number of organisms giving } \\
50 \text { per cent mortality }\end{array}$} \\
\hline Case & $\begin{array}{l}\text { Cerebrospinal } \\
\text { fluid strain }\end{array}$ & $\begin{array}{l}\text { Nasopharyngeal } \\
\text { strain }\end{array}$ \\
\hline $\begin{array}{l}\text { J. M. } \\
\text { B. R. } \\
\text { J. C. }\end{array}$ & $\begin{array}{r}7 \\
147 \\
11\end{array}$ & $\begin{array}{r}10 \\
275 \\
352\end{array}$ \\
\hline
\end{tabular}

parently considerable difference between the endpoints for the nasopharyngeal and cerebrospinal fluid strains, the method of titrating virulence is probably not accurate enough to make this difference significant.

The few Group II strains from cases showed no striking differences from the Group I strains, as may be seen in Table II. Three were highly virulent, 1 was moderately virulent, and 1 was avirulent. In contrast, 9 of the 10 Group II carrier strains were of low virulence. 
There was no correlation between virulence of the organisms, as determined by this method, and severity of the disease in patients from whom the organisms were isolated. The mildest case in the series, almost lacking in subjective symptoms, possessed one of the most virulent organisms, while another patient with extreme prostration and a stormy clinical course yielded an organism which was almost avirulent by mouse titration.

The storage of meningococci in the frozen state did not affect their virulence for mice. Several strains were tested after 8 months of storage and were found to be of the same order of virulence as at the time of original isolation. In contrast, two strains which had been maintained on blood agar for several months underwent a pronounced diminution in virulence. This diminution was accompanied by loss of the property of capsular swelling in specific antisera.

7. Survival or growth in fresh normal human serum. A wide variation was observed in the ability of different strains of meningococci to survive or to grow in fresh normal serum from a single individual. This property was not related to the virulence of the organisms for mice, nor to the specific group of the strain. The results with 12 strains isolated from cases of meningitis are shown in Table IV. It may be seen that all degrees of survival were exhibited by strains of the same mouse virulence and of the same group. The least virulent strain $(\mathrm{Lu})$ and the most virulent strain (Number 4), for example, possessed

TABLE IV

Ability of meningococci to survive in fresh, normal human serum in $1: 2$ dilution

\begin{tabular}{|c|c|c|c|c|c|c|c|c|}
\hline \multirow{2}{*}{ Strain } & \multirow{2}{*}{ Group } & \multirow{2}{*}{ Virulence * } & \multicolumn{6}{|c|}{ Dilution of organisms $\dagger$} \\
\hline & & & $10^{-1}$ & $10^{-2}$ & $10^{-8}$ & $10^{-4}$ & $10^{-6}$ & $10^{-6}$ \\
\hline $\begin{array}{c}2 \\
30 \\
21 \\
4 \\
\mathrm{Lu} \\
\mathrm{Do} \\
8 \\
\mathrm{Ro} \\
\mathrm{Cz} \\
\mathrm{Mc} \\
\mathrm{Deo} \\
\mathrm{Gi}\end{array}$ & $\begin{array}{l}\text { I } \\
\text { I } \\
\text { I } \\
\text { I } \\
\text { I } \\
\text { I } \\
\text { I } \\
\text { I } \\
\text { II } \\
\text { II } \\
\text { II } \\
\text { II }\end{array}$ & $\begin{array}{c}10 \\
43 \\
7 \\
1 \\
>10,000 \\
6 \\
275 \\
1200 \\
18 \\
80 \\
500 \\
9000\end{array}$ & $\begin{array}{l}+ \\
0 \\
+ \\
+ \\
+ \\
+ \\
+ \\
+ \\
+ \\
+ \\
+ \\
+\end{array}$ & $\begin{array}{l}+ \\
0 \\
+ \\
+ \\
+ \\
+ \\
+ \\
+ \\
+ \\
+ \\
+ \\
+\end{array}$ & $\begin{array}{l}0 \\
0 \\
+ \\
+ \\
+ \\
0 \\
+ \\
+ \\
+ \\
0 \\
+ \\
0\end{array}$ & $\begin{array}{l}0 \\
0 \\
+ \\
+ \\
+ \\
0 \\
0 \\
+ \\
+ \\
0 \\
+ \\
0\end{array}$ & $\begin{array}{l}0 \\
0 \\
+ \\
+ \\
+ \\
0 \\
0 \\
+ \\
0 \\
0 \\
+ \\
0\end{array}$ & $\begin{array}{l}0 \\
0 \\
+ \\
+ \\
+ \\
0 \\
0 \\
+ \\
0 \\
0 \\
+ \\
0\end{array}$ \\
\hline
\end{tabular}

* Virulence expressed as number of organisms producing 50 per cent mortality in mice, employing mucin.

$\dagger^{-6}=50$ organisms in $0.05 \mathrm{ml}$. equal ability to survive. On the other hand, 2 strains which failed to survive (Number 2 and $\mathrm{Gi}$ ) had virulence titers of 10 and 9000 , respectively. A similar variation was encountered among the other strains tested, in which were included 10 Group II carrier organisms of low virulence for mice. Some of the latter strains grew in the highest dilutions, while others failed to survive in any dilution.

When the nasopharyngeal and cerebrospinal fluid strains from 3 cases of Group I infection were compared, it was found that the nasopharyngeal strains were somewhat less able to survive in each instance (Table V). It should be noted,

TABLE $\mathbf{v}$

Comparison of the survival or growth in fresh, normal human serum of strains of Group I meningococci from cerebrospinal fluid and nasopharynx of the same individuals

\begin{tabular}{|c|c|c|c|c|c|c|c|}
\hline \multirow{2}{*}{ Case } & \multirow{2}{*}{ Source of strain } & \multicolumn{6}{|c|}{ Dilution of organism * } \\
\hline & & $10^{-1}$ & $10^{-2}$ & $10^{-8}$ & $10^{-6}$ & $10^{-6}$ & $10^{-6}$ \\
\hline J. M. & $\begin{array}{l}\text { Cerebrospinal fluid } \\
\text { Nasopharynx }\end{array}$ & + & $\stackrel{+}{+}$ & + & + & $\stackrel{+}{0}$ & $\stackrel{+}{0}$ \\
\hline B. $\mathbf{R}$. & $\begin{array}{l}\text { Cerebrospinal fluid } \\
\text { Nasopharynx }\end{array}$ & $\dot{t}$ & + & + & $\stackrel{+}{0}$ & $\stackrel{+}{0}$ & $\begin{array}{l}\mathbf{0} \\
\mathbf{0}\end{array}$ \\
\hline J. C. & $\begin{array}{l}\text { Cerebrospinal fluid } \\
\text { Nasopharynx }\end{array}$ & $\stackrel{+}{+}$ & + & + & + & + & $\stackrel{+}{0}$ \\
\hline
\end{tabular}

${ }^{*} 10^{-}=50$ organisms in $0.05 \mathrm{ml}$.

however, that the differences were relatively small as compared with the degree of variation among cerebrospinal fluid strains from other cases.

\section{DISCUSSION}

The bacteriological study of 39 strains of meningococci isolated under both epidemic and endemic conditions has revealed several points of interest. During the Halifax epidemic $(2,3)$, there were 93 cases within a period of 6 months. Unfortunately, the strains from all of these cases were not available for examination, but of the 12 strains tested in this laboratory, all were found to be Group I meningococci. Of the sporadic cases in Boston, 6 were due to Group I strains and 5 to Group II strains.

Single nasopharyngeal cultures of 60 contacts of 17 epidemic cases of meningitis yielded 3 Group I strains and 10 Group II strains. All 
but 1 of the Group II carriers were found in a single household, comprising 17 members. No Group I carriers were found in this household. The observed incidence of Group I carriers in Halifax was low ( 5 per cent), possibly because only 1 culture was taken from each contact, and may not be indicative of the true carrier situation. Group I strains were isolated from the nasopharynx of 2 contacts of an endemic case of meningitis due to a Group I organism.

The morphology, fermentations, and oxidase reactions of these strains were found to be similar, regardless of their source and group. Minor differences in size of colonies were noted in 6 Group II carrier strains, and slight pigmentation developed with 2 of these strains.

The quellung reaction was found to be a reliable and satisfactory method of identifying the Group I strains, and in every instance was confirmed by the agglutination technique. It was also noted that the capsular reaction could be enhanced by permitting the organisms, before they were stained for examination, to grow for from 2 to 4 hours in rabbit antiserum, inactivated by heat. This procedure offers obvious advantages in grouping strains from the cerebrospinal fluid of patients. Another group of meningococci, termed II A (13), can be identified by the quellung reaction. Thus far, capsular swelling has not been described with the other, probably heterogeneous, strains comprising Group II.

Prior to the introduction of the use of mucin in virulence tests of the meningococcus by Miller (14), the estimation of virulence in mice required massive doses of organisms and the results did not permit easy and dependable comparisons between strains on a quantitative basis. With the use of mucin, relatively quantitative comparisons have become possible, and a number of workers have studied the virulence of different groups of meningococci, from cases, contact carriers, and non-contact carriers. If the virulence for mice could be taken as an index of pathogenicity for man, then differences of considerable degree might be expected in such comparisons.

Rake (15), in an extensive study of carrier strains of meningococci, found Group I strains to be of high virulence, Group II strains less virulent, and atypical strains very low in virulence.
In his experience, carrier strains of any given type tended to be of somewhat lower virulence than case strains of the same type. Silverthorne and his co-workers (16) reported that 90 per cent of the meningococci isolated from cases and contact carriers were virulent, while the majority of strains from non-contact carriers were avirulent. Most of the organisms studied by Silverthorne were Group II (75 out of 79). The Group II strains from carriers in the present studies were found to be non-virulent, but since these carriers were encountered during an epidemic of Group I meningococcal meningitis it seems reasonable to regard them as non-contact carriers. On the other hand, the Group I carrier strains were from contact carriers and were of the same virulence as the Group I strains from cases.

If mouse virulence indicates pathogenicity for man, these results would suggest that during epidemics, carriers are in some manner protected against the virulent organisms which they harbor, while non-contact carriers may have organisms which are simply accidental saprophytes, lacking in potential infectivity. In the paper following (4), it will be shown that Group I contact carriers possess relatively high titers of specific agglutinins, which are lacking in the sera of Group II carriers.

It has not yet been shown, however, that the mouse-virulence test actually constitutes a measure of pathogenicity for man. On theoretical grounds, the ability of a strain of meningococcus to survive or grow in normal human serum might also be taken as an indication of potential invasiveness, yet in this investigation the results of the two tests are at complete variance. It is conceivable that in both tests the results are determined by certain unrelated properties of the organisms which may contribute to the initiation of infection in man, but the problem is still unsolved. The ability of an organism to survive in a given normal serum will, of course, depend on the bactericidal action of that serum, which may or may not be due to specific antibodies. Variations between sera from different individuals would therefore be expected. Some property inherent in the organism, however, must be responsible for the observed results with different strains in the same serum. It is perhaps significant that 
with strains from cases of meningitis, no direct correlation could be noted between either mouse virulence or survival in a single normal human serum and the severity of the clinical infection, the epidemic or endemic origin, or the serological group. There was also no apparent correlation between mouse virulence and source of the culture. Nasopharyngeal strains from 3 cases of meningitis, however, were somewhat less able to survive or grow in fresh normal human serum than were the cerebrospinal fluid strains from the same patients. Further study is necessary to determine whether or not this observation is of significance.

\section{SUMMARY}

1. Twelve strains of Group I meningococci were isolated from cases during an epidemic of meningitis. Seven Group I and 5 Group II strains were isolated from endemic cases. Nasopharyngeal cultures of a group of contacts in the epidemic area yielded 3 Group I strains and 10 Group II or atypical strains. Group I strains were isolated from 2 contacts of a sporadic case of Group I infection.

2. Quellung in specific antiserum was a satisfactory method for the rapid identification of Group I strains, and agreed in every instance with typing by agglutination. Quellung was found to be enhanced by culturing the organisms in specific antiserum for several hours. This reaction was not observed with the Group II strains.

3. The morphology, fermentations, and oxidase reaction were typical of meningococci in all of the 39 strains studied.

4. All except 2 of the Group I strains displayed a high virulence for mice. There was no significant difference between the virulence of nasopharyngeal and cerebrospinal fluid strains of Group I, between the Group I strains from cases and contact carriers, nor between the Group I strains from epidemic and sporadic cases.

5. Three of the 5 Group II strains from the cerebrospinal fluids of cases were highly virulent for mice, while 2 were of low virulence. In contrast, all of the carrier strains of Group II or atypical meningococci were of low virulence; these strains may represent non-contact carrier organisms, since they were isolated during a Group I epidemic.
6. No correlation was observed between the mouse virulence of strains from the cerebrospinal fluid of patients and the severity of the disease.

7. Wide variation was found in the ability of different strains of meningococci to survive or grow in fresh, normal, human serum, and no correlation was seen between the degree of survival and either the specific group of the organism or its virulence for mice. The nasopharyngeal strains of 3 cases were somewhat less able to survive than the cerebrospinal fluid strains from the same individuals.

The authors are indebted to Mrs. Muriel B. Stone and Miss Mary Glover for technical assistance.

Certain of the strains of meningococci and sera of patients used in this study were obtained during a survey of epidemic diseases in Halifax, Nova Scotia, undertaken by a group from Harvard Medical School, headed by Dr. J. Howard Mueller. The assistance and cooperation of $\mathrm{Dr}$. A. R. Morton of the Office of Public Health and Welfare, Halifax, and of Dr. D. J. MacKenzie, Director of the Provincial Public Health Laboratory, are gratefully acknowledged.

\section{BIBLIOGRAPHY}

1. Dingle, J. H., and Finland, M., Diagnosis, treatment and prevention of meningococcic meningitis. War Med., 1942, 2, 1.

2. Dingle, J. H., Thomas, L., and Morton, A. R., Treatment of meningococcic meningitis and meningococcemia with sulfadiazine. J. A. M. A., 1941, 116, 2666.

3. Wheeler, S. M., and Morton, A. R., Epidemiological observations in the Halifax epidemic. Am. J. Pub. Health, 1942, 32, 947.

4. Thomas, L., Smith, H. W., and Dingle, J. H., Investigations of meningococcal infection. II. Immunological aspects. J. Clin. Invest., 1943, 22, 361.

5. Thomas, L., and Dingle, J. H., Investigations of meningococcal infection. III. The bactericidal action of normal and immune sera for the meningococcus. J. Clin. Invest., 1943, 22, 375.

6. Mueller, J. H., and Hinton, J., A protein-free medium for primary isolation of the gonococcus and meningococcus. Proc. Soc. Exper. Biol. and Med., 1941, 48, 330 .

7. Strauss, E., Lowell, F. C., and Finland, M., Observations on the inhibition of sulfonamide action by para-aminobenzoic acid. J. Clin. Invest., 1941, 20, 189.

8. Janeway, C. A., Method for obtaining rapid bacterial growth in cultures from patients under treatment with sulfonamides. J. A. M. A., 1941, 116, 941.

9. Gordon, M. H., and Murray, E. G., Identification of the meningococcus. J. Roy. Army M. Corps, 1915, 25, 411 . 
10. Clapp, F. L., Phillips, S. W., and Stahl, H. J., Quantitative use of Neufeld reaction with special reference to titration of Type II antipneumococcic horse sera. Proc. Soc. Exper. Biol. and Med., 1935, 33, 302.

11. Gordon, J., and McLeod, J. W., The practical application of the direct oxidase reaction in bacteriology. J. Path. and Bact., 1928, 31, 185.

12. Reed, L. J., and Muench, $H .$, A simple method of estimating fifty per cent end-points. Am. J. Hyg., 1938, $27,493$.

13. Branham, S. E., and Carlin, S. A., Comments on a newly recognized group of the meningococcus. Proc. Soc. Exper. Biol. and Med., 1942, 49, 141.

14. Miller, C. P., Experimental meningococcal infection in mice. Science, 1933, 78, 340.

15. Rake, G., Studies on meningococcus infection. VII. The study of an isolated epidemic. J. Exper. Med., 1935, 61, 545. Some features of the epidemiology of meningococcus meningitis. Canad. Pub. Health J., 1936, 27, 105.

16. Silverthorne, N., Fitzgerald, J. G., and Fraser, D. T., Studies on the meningococcus and meningococcus infection. J. Pediat., 1939, 15, 491. 